\title{
НАРУШЕНИЯ ПСИХИЧЕСКОЙ ДЕЯТЕЛЬНОСТИ В КЛИНИЧЕСКОЙ КАРТИНЕ КРАНИОФАРИНГИОМ У ВЗРОСЛЫХ
}

\author{
1,2Сиднева Ю.Г., 'Астафьева Л.И., 'Зайцев О.С., 'Калинин П.Л., 'Ураков С.В., 'Кутин М.А., 'Кадашев Б.А., \\ 'Воронина И.А., 'Шкарубо А.Н., 'Фомичев Д.В., 'Андреев Д.Н., 'Шарипов О.И. \\ 1 ФГАУ «НМИЦ Нейрохирургии имени академика Н.Н.Бурденко» МЗ РФ, Москва \\ 2ГБУЗ «НИИ Неотложной Детской Хирургии и Травматологии» ДЗ г. Москвы
}

\begin{abstract}
Краниофарингиомы (КФ) - доброкачественные образования головного мозга дизэмбриогенетического генеза, чаще встречаются у детей, но могут проявляться и во взрослом периоде (9\% и 2-3\% ото всех опухолей головного мозга). Различаются топографо-анатомическим вариантом расположения и соответствующей клиникой, которая включает общемозговую, неврологическую и нейроэндокринную симптоматики; помимо этого выявляются и психические нарушения. По данным литературы расстройства психической деятельности варьируют от 6 до 100\%.
\end{abstract}

ЦЕЛЬ: изучить психические нарушения у взрослых пациентов с КФ.

МАТЕРИАЛЫ И МЕТОДЫ: 130 взрослых (18-76 лет, медиана 42士2,14; 64 женщины и 66 мужчин), впервые поступившие в НМИЦ (2007-2018).

КФ (Коновалов А.Н. и соавт., 1982) разделились на группы: 1 - с эндо-/эндосупраселлярной 29; 22,3\%; 2 - со стебельной 48; 36,9\%; 3 - со стебельно-вентрикулярной 38; 29,2\%; 4 - с интра-вентрикулярной $15 ; 11,5 \%$.

Основной метод - клинико-психопатологический, также учитывались данные комплексного обследования с эндокринологическим, неврологическим, нейроофтальмологическим и рентгенологическим исследованиями.

дополнительно: 1) Шкала Общего Ухудшения (Global Deterioration Rating, B. Reisberg et al, 1982); 2) индекс Карновского (D.A. Karnofsky, J.H. Burchenal, 1949).

РЕЗУЛЬТАТЫ: психические нарушения были у 111 пациента (85,3\%): эмоционально-волевые 85 пациентов (65,3\%), мнестические - 77 (59,2\%), изменения личности - 76 (58,4\%), пароксизмальные - 58 (44,6\%), расстройства сна и сновидений - 57 (43,8\%), расстройства сознания - 26 (20\%). Гипопитуитаризм/пангипопитуитаризм, несахарный диабет выявлены у $89 \%$.

Расстройства психики выявлялись: в 61,8\% с эндосупраселлярной, в 83,4\% со стебельной, в 100\% с экстра-интра- и интра-вентрикулярными КФ. Психопатологические симптомы/синдромы сочетались друг с другом и преобладали в той или ной степени при разных вариантах КФ. Наиболее грубые психические нарушения: корсаковский синдром, аспонтанность, акинетический мутизм, личностный дефект в 21,5\% (28 пациентов), чаще с экстраинтра-вентрикулярной КФ. При этой же локализации КФ преобладали пациенты с трудностями самостоятельного обслуживания и социальной дезадаптацией (50\%) (индекс Карновского 10-40\%, шкала GDR 6-7 баллов).

ВЫВОдЫ: психические расстройства в клинической картине КФ выявляются у 85,3\% до операции, определяются локализацией опухолевого поражения в диэнцефальной области, распространением и воздействием образования на гипоталамо-таламические структуры, лимбическую системы, III желудочек. В зависимости от топографо-анатомического расположения КФ психопатология встречается в $61,8 \%$ с эндосупраселлярной, в 83,4\% со стебельной, в 100\% с экстра-интра- и интра-вентрикулярными КФ.

Выраженность нарушений психической деятельности обусловлена особенностями роста опухоли в III желудочек, вовлечением в патологический процесс лимбических и таламо-гипоталамических регулирующих структур головного мозга, наличием нейроэндокринных расстройств, сопутствующей гипертензионно-гидроцефальной симптоматикой.

КЛЮЧЕВЫЕ СЛОВА: Краниофарингиома, психические нарушения, диэнцефальное поражение, нейроэндокринные нарушения, корсаковский синдром, нарушения памяти, эмоциональные нарушения, личностные изменения, поведенческие нарушения. 